\title{
Clinical application of triangular parabolic PEEK mesh with hole button produced by combining CAD, FEM and 3DP into cranioplasty.
}

\author{
Rongde Zhong ${ }^{1,2 \#}$, Ziqiang $\mathrm{Xie}^{3 \#}$, Yuqing $\mathrm{Liao}^{3 \#}$, Yunqing $\mathrm{Li}^{4}$, Chiwen Huang ${ }^{\text {* }}$ \\ ${ }^{1}$ Department of Neurosurgery, the Tenth People's Hospital of Shanghai, Shanghai, PR China \\ ${ }^{2}$ Huashan Hospital North, Fudan University, Shanghai, PR China \\ ${ }^{3}$ Medical College of Nanchang University, Nanchang, PR China \\ ${ }^{4}$ Department of Gastroenterology, the Tenth People's Hospital of Shanghai, Tongji University, Shanghai, PR China \\ ${ }^{5}$ Department of Neurosurgery, Songgang People's Hospital of Baoan District, Shenzhen, PR China
}

\begin{abstract}
Background: Cranioplasty (CP) helps to restore the integrity of the skull and the stability of the inner brain structure, to greatly improve the aesthetic and to reduce the concerns caused by the weakening of the brain's protection. However, how to achieve less complications while maintain a high aesthetic effect of CP has always been the pursuits of the neurosurgeons, manufactures and researchers.

Objectives: Using Computer-Aided Design (CAD), Finite Element Methods (FEM) and 3D printing (3DP) to produce a customized triangular parabolic polyetheretherketone (PEEK) mesh for patients with skull defect who need Cranioplasty.

Patients and methods: A patient whose left frontal-temporal-parietal temporal skull had defects, need $\mathrm{CP}$, and a customized triangular parabolic polyetheretherketone (PEEK) mesh with hole button prepared by CAD, FEM and 3DP is proposed for CP. After cycled individualized design and mechanical comparison analysis, the implant is formed by 3DP.

Results: A triangular parabolic PEEK mesh with 5-hole button produced by CAD and A vertical $2000 \mathrm{~N}$ static force was applied in the central area of a $7 \mathrm{~mm}$ diameter of implants, then the maximum stress of 5-lock-botton mesh (triangular paraboloid mesh with lock button model $\sigma=5.7228$ e6; defective bone $\sigma=4.1904$ e6) and maximum strain of 5-lock-botton mesh (triangular paraboloid mesh with lock button model=9.053e-7; defective bone $\varepsilon=1.9363 \mathrm{e}-7$ ) was obtained by stress-strain analysis, the corresponding stress nephogram and stress ribbon image showing that the concentrated force distribution is relatively uniform.

Conclusion: Triangular parabolic PEEK mesh with hole button had a high biomechanical performance and aesthetic effect for $\mathrm{CP}$.
\end{abstract}

Keywords: De-compressive craniectomy, Cranioplasty, Polyetheretherketone, Computer-aided design, Finite element methods, 3D printing.

Accepted on May 21, 2018

\section{Introduction}

A high intracranial pressure caused by a severe craniocerebral injury, a diffuse cerebral edema after a large area of malignant cerebral infarction or cerebral swelling, will reduce cerebral perfusion and cerebral blood flow that will make cerebral anoxia, which again increase intracranial pressure, such a vicious circle can easily lead to a hernia which is fatal to the patients. High intracranial pressure is an independent risk factor leading to high mortality rate in patients [1-4]. Early decompressive craniectomy (DC)-removal of the bone flap and cut of the meninges can increase potential intracranial space thus to reduce intracranial pressure increase and prevent hernia, and can also improve cerebral perfusion, cerebral blood flow and cerebral oxygen supply. Its postoperative mortality rates, vegetative state rates and disability rates were much lower compared with a conservative treatment's. DC is a common surgery confirmed by neurosurgery and can save the patient's life [5-7]. Survived patients can have cognitive dysfunction, cerebral hemodynamic changes, skull defect syndrome and other complications due to skull defects thus $\mathrm{CP}$ is necessary to most of them. The final goal of CP is not only to restore the skull's shape but also to reshape brain tissue, cerebrovascular, and provide a physical protection for brain thus to improve the clinical symptoms and neurological dysfunction of patient, to prevent secondary damages of brain 
tissue on the area of skull defects such as hydrocephalus, subdural effusion, cerebral infarction, etc. [8-10]. Autologous bone skull repair has excellent immuno-compatibility but limited by the number of bone flap, morphology, storage and bone re-sorption of post-implantation. It has a rate of up to $50 \%$ for total postoperative complication, meanwhile the donor site is susceptible to a trauma $[11,12]$. Titanium mesh skull repair has been introduced since 1965 and used until now, but limited by its elastic modulus and high thermal conductivity, uneven force distribution for mechanical impact after implantation, furthermore, has a rate of up to $27.8 \%$ of postoperative complications [13]. The cover-like titanium mesh skull repair has many shortcomings in clinical practice: 1) Titanium mesh size and shape does not match defect area;2) There will be many re-shaping's of titanium mesh during operation thus will destroy its integrity and mechanical properties; 3) To make titanium mesh fit more solid without any buckling, there will be more titanium nails needed thus will increase the cost of treatment; 4) After surgery, it is prone to be deformation of titanium mesh, displacement, fracture, titanium wire exposure, nails loosen caused by force and other risks, leading to infection thus need to remove the titanium mesh again for a second repair. Tsouknidas et al. contend that foreign body implants must meet a series of important criteria of such as biocompatibility, direct contact between repair and bone edge, and a high mechanical stability etc. [14]. PEEK polymer materials have characteristics of radiation resistance, corrosion resistance, high temperature resistance, high compression resistance, high biocompatibility, X-ray transmittance and others, which potentially can be alternative to metal or ceramic material $[15,16]$. We use the PEEK material, combing CAD, FEM and 3DP technology to make a triangular parabolic mesh with a hole lock button for skull repair. The purpose is to propose a new method to customize the skull repair implant, to greatly realize: 1) Easy to implant and has excellent anatomical accuracy and aesthetic effects; 2) Brain structure and brain protection function recovery; 3) Less postoperative complications.

\section{Materials and Methods}

\section{Clinical features}

Volunteer, male, age of 50, admission by a "3 h' loss of consciousness caused by car accident"; Physical examined: coma, GCS score of 6 points, the left side of the pupil dilated, diameter is $4 \mathrm{~mm}$, fixed (to light), the right side of the pupil is $2.5 \mathrm{~mm}$, light reaction was slowly. Admission diagnosis: 1) Traumatic hernia of brain; 2) Traumatic frontal lobe haemorrhage; 3) Traumatic subdural hemorrhage.an actively preoperative preparation was done after admission, the brain hematoma removal was done (frontal-temporal-parietal lobe de-compressive craniectomy+monitoring probe was planted to monitor the intracranial pressure) under general anaesthesia. One month following surgery, the intracranial status was stable; the patient had a good recovery, and then transferred to a rehabilitation hospital for a rehabilitation therapy. Return for a proposed of CP after 3 months, Computer Topographies (CT) examination (Figure 1) of brain again.

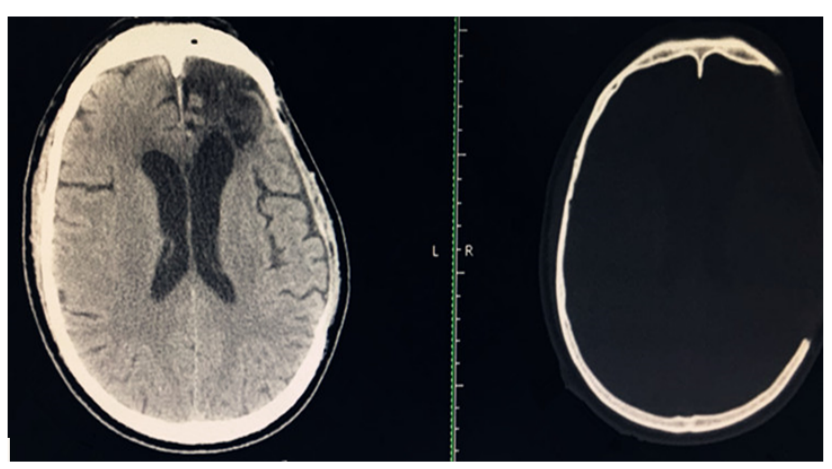

Figure 1. 3 months after DC surgery, the left frontal-temporalparietal temporal skull had defects, need to conduct CP to resume the integrity of the skull.

\section{Image and digital model}

Data of the patients' trauma, acquired through CT, provide sufficient information with regard to the defect contour profile, thus allowing a thorough preoperative evaluation whilst ensuring excellent implant precision. With the patient in supine position, head fixed, the canthomeatal line as the reference plane, 64 rows shadow UCT-760 spiral CT was utilized for continuous scanning on the brain (pitch of $0.625 \mathrm{~mm}$, thickness of $2 \mathrm{~mm}$, layer spacing of $2 \mathrm{~mm}$, collimation width of $20 \mathrm{~mm}$. Rotation time of $1 \mathrm{~S}, 512 \times 512$ matrix), 178 pieces of the images was obtained.

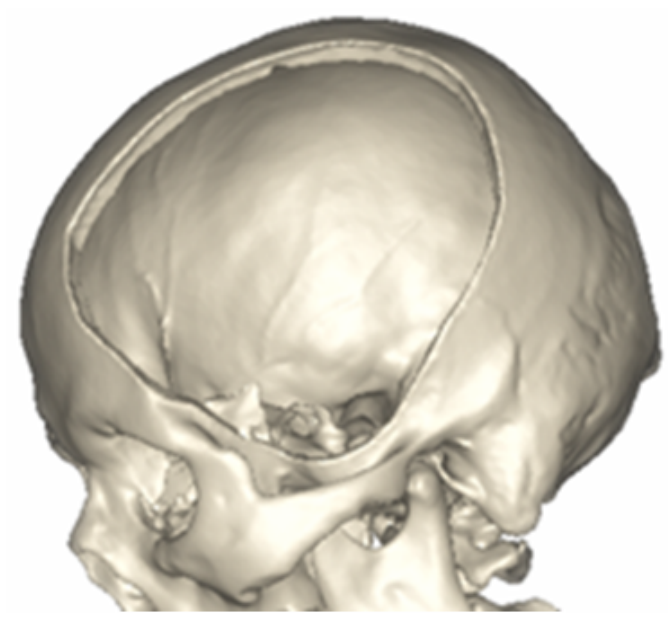

Figure 2. 3D anatomical structure image of the skull defect (left frontal-temporal-parietal skull defect, defect area of $10.5 \times 12.5 \mathrm{~cm}$ ).

The images will be saved in DICOM format and imported into 3D reconstruction software named MIMICS 17.0 (Belgium materials) for images threshold division and images segmentation (HU1250-3515) to obtain the defective skull MASK. And then "DRAW" and "ERASE" of the "EDIT" function keys was applied on the MASK in the software, thus the unrelated tissue and constructed defect of the mask can be removed layer by layer to further distinguish and separate the skull and to get more accurate data. Function keys ("3D CALULATION", "SMOOTH" and "WRARP") was also 
applied on the mask to generate pictures of clear, intuitive and reappeared the three-dimensional structure of skull defects (Figure 2). It was saved in STL format.

Afterwards, it was imported into 3-MATIC software (Belgium materials) to draw a design of repair mesh model according to the principle of axisymmetric mirror, to draw a design of lock bottom according to the clinical experience and the actual curvature of the bone, and then to get the model of the triangular parabolic mesh with hole lock button, which to be imported into software Geomagic Studio2013 (US Geomagic) for materialization, noise reduction processing, elimination of the abnormal parts in form, while repairing holes and chamfering corners [17]. Finally, it is imported into UG8.5 software (Germany Siemens PLM Software) for assembly of components (Figure 3) and format conversion. And converted format was exported in XT.

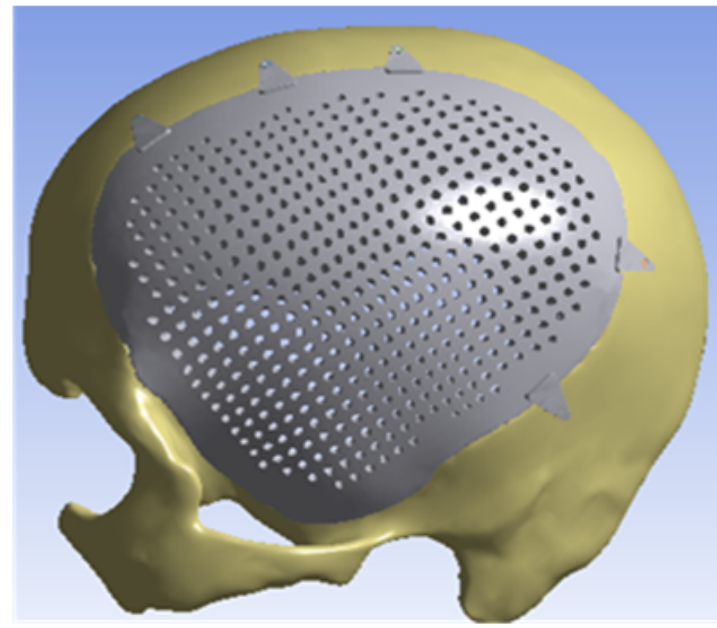

Figure 3. Model of triangular parabolic mesh with hole lock button (mesh area of $10.5 \times 12.5 \mathrm{~cm}$, hole diameter of $2.1 \mathrm{~mm}$, hole spacing of $2.4 \mathrm{~mm}$, edge part been materialized, lock hole diameter of $2 \mathrm{~mm}$ ).

\section{FEM model and analysis}

The design of the implant requires special consideration of its biomechanical properties-long-term mechanical stability and resistance to stress and strain, which is one of the key factors to ensure the success of implantation.

Therefore, the widely used FEM to assess biomechanical properties and to prejudge the success of the implantation was adopted; After the model is imported into ANSYS-workbench 17.0 software (US ANSYS) in XT format, the definition of material properties (Table 1) and mesh segmentation need to be finished before FEA (Finite Element ANSYS FEA).

In this study, we utilized a tetrahedral mesh and swept mesh segmentation, in which the number of nodes is 1586622 , the number of units is 1019930 (Figure 4).

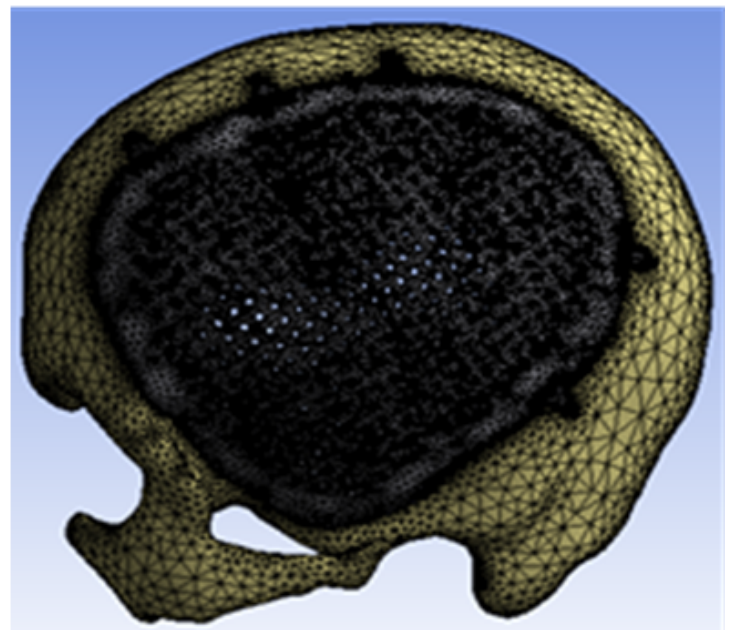

Figure 4. The model of tetrahedral mesh and swept mesh segmentation, the number of nodes is 1586622; the number of units is 1019930.

Table 1. The characteristics and model parameters of PEEK and skull.

\begin{tabular}{llll}
\hline Materials & $\mathbf{E}(\mathbf{M P a})$ & $\mathbf{V}$ & $\mathbf{P}\left(\mathbf{g} / \mathbf{c m}^{3}\right)$ \\
\hline PEEK & 4000 & 0.4 & 1.3 \\
\hline Skull & 4000 & 0.3 & 1.45 \\
\hline
\end{tabular}

Skulls and implants were considered as isotropic, homogeneous and continuous linear elastomer. A vertical 2000 $\mathrm{N}$ static force was applied in the central area with a $7 \mathrm{~mm}$ diameter of the model of Triangular Parabolic Mesh with hole lock button to simulate the stress of the skull applied by heavy smash, car hit in a real life after the craniotomy. Equivalent (Von-mises) stress $(\sigma)$ and total deformation $(\varepsilon)$ of the model of Triangular Parabolic Mesh with hole lock button and the defect skull model were obtained respectively by static mechanics analysis. It will be verified according to the equation $\mathrm{F}=\mathrm{K} \times \varepsilon$ ( $F$ is the load array, $\mathrm{K}$ is the stiffness matrix, $\varepsilon$ is the elastic strain). If the biomechanical mechanics is highly satisfied-the distribution of concentrated force is even and with low $\sigma$ and $\varepsilon$, then the next step is 3DP.

If the biomechanical mechanics results are less satisfactory, circular microstructure reconstruction and analysis of the model of the repair need to be done before 3DP. In the initial analysis of this model, the concentration of force is not even, and it is concentrated in the forehead, orbital and temporalfurthermore, $\sigma$ and $\varepsilon$ was high (Figure 5). Reconstruct and delete the parietal lobe-lock button, move the foreheadparietal lobe lock button forward and increase the $2 \mathrm{~mm}$ thickness of ring to reduce the $\sigma$ value and uniformize force distribution (Figure 6). Therefore, provide sufficient mechanical strength and stiffness to substitute initially for wound contraction forces and bone integrity over time. 


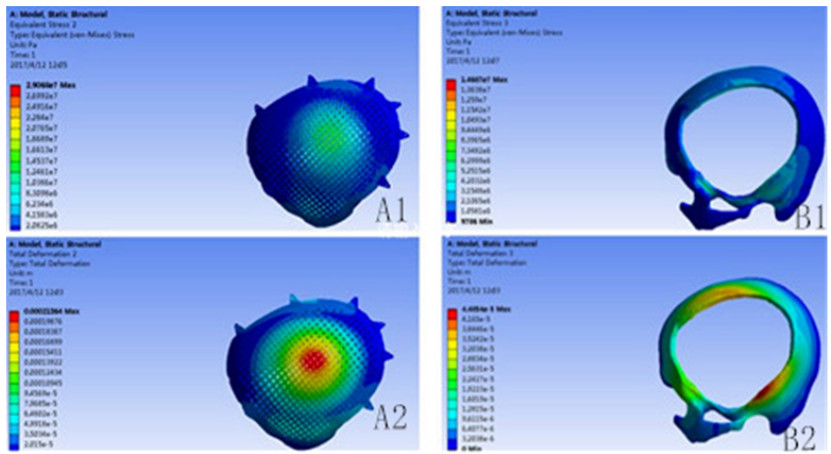

Figure 5. To identify the areas showing higher stress concentration in which failure may occur, the $\sigma$ and $\varepsilon$ representative model of triangular parabolic mesh with hole lock button and defective skull were selected. 6 lock button model $A$ and defective skull model B, Analysis of $A 1 \sigma=2.9068 e 7, A 2 \varepsilon=2.1364 e-4 ; B 1 \sigma=1.4687 e 7, B 2$ $\varepsilon=4.4854 e-5$.

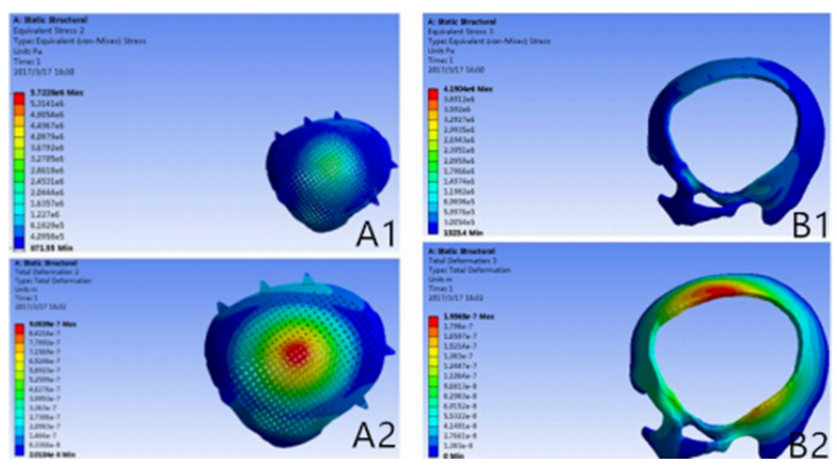

Figure 6. 5 lock button model $A$ and defective skull model $B$, analysis A1 $\sigma=5.7228 e 6, A 2 \varepsilon=9.053 e-7 ; B 1 \sigma=4.1904 e 6, B 2 \varepsilon=1.9363 e-7$.

\section{DP and post-processing}

Forming or manufacturing of the model is another important factor that affects the biomechanical properties and precision of the repair, especially for orthosis with complex structural. When the model achieves satisfactory results within CAD and FEA, the defective skull model and the repair model are imported into 3D printing system software to "sliced" into thin horizontal layers, with the tool path specified for each layer, the "sliced" date are used to instruct the selective laser sintering 3D printing machine (China are 3D) layer by layer to build an implant. Post-processing includes: reassembly of implants and defective skulls to reconfirmation of fitness and curvature, polishing, packaging, and UV disinfection.

\section{Additional experiments: steel ball impact test}

The same patient's repairs was manufactured through the dry pressing of the 3-dimensional titanium mesh and PEEK mesh produced by combining CAD, FEM and 3DP. Free fall impact of a $360 \mathrm{~g}$ ball from a height of $50 \mathrm{~cm}$ is applied at the center of the mesh, 3 times of which repeated, and deformation the mesh is compared (Figure 7).

\section{Discussion}

Skull defects are resulted from DC for brain trauma, malignant cerebral infarction, brain and/or skull tumors, this defect normally require a second skull repair surgery to restore brain protection, physical aesthetics, cerebral blood circulation and neurological function. To pursue the demand for more aesthetic, high mechanical properties and lower side effects prosthetic with long-term, having lead manufacturers, researchers, and neurosurgery professionals to search for technological improvements of restorative materials and craftwork fabrications; There are various commercial prosthetic introduced on the market but their designs differ in terms of architecture or (and) materials. Anyhow, neither their involve implant with Triangular parabolic hole locking button net nor making combined the technology of CAD, FEM and 3DP. In this study, we utilized PEEK materials and combined the technology of CAD, FEM and 3DP to make the skull repair.

PEEK is new poly-crystalline, high-temperature thermoplastic, non-degradable material, and a linear polymer of which macromolecule main chain are composed of aryl, ketone and ether bond. Stable chemical structure makes it high temperature $\left(>300^{\circ} \mathrm{C}\right)$ resistant and insulated, without the concerns for thermal degradation and heat, electrical conduction, and its main properties can still be maintained after 3000 times of cycled high-pressure steam sterilization at $134^{\circ} \mathrm{C}$. According to a lot of references, PEEK material has an outstanding performance on resistance to hydrolysis and chemical corrosion, and is almost insoluble in any traditional solvent except in $98 \%$ of sulfuric acid. Boinard et al. found that PEEK is water-soluble (room temperature) with a solubility of $0.5 \mathrm{~W} / \mathrm{w}[15,16,18]$, without significant absorption after longterm salt water immersion. And it is also radiation-resistant, ray-permeable and MRI-compatible. Due to the attenuation of the rays of titanium repair, it will result in some pseudo shadow in the CT and X-ray image. HM Li and others utilized electron spin resonance to study free radical attenuation of PEEK and discovered that there's no radical $20 \mathrm{~min}$ after radiation (600 kGray) on PEEK, so PEEK was not considered a secondary radiation source after gamma-ray sterilization $[19,20]$. PEEK has outstanding advantages on the biocompatibility, no toxin, no immunity, no allergens. Rivard et al. implanted PEEK fusion device in the rabbit's intervertebral space for a biocompatibility test, and found out that there no adverse consequences such as tissue necrosis, nerve swelling, fat dissolution, border wear and others in 1, 4, 12 weeks after the operation and inflammation cell responses were absorbed after 12 weeks. His study also supported that fibrous tissue and blood vessels can climb in the PEEK fuse [19]. Torchrick et al. porous PEEK mesh cell culture experiments also showed consistent results: porous PEEK mesh can promote cell proliferation, bone growth and angiogenesis, improve bone integration, of which integration effect is better than titanium mesh's [21]. In 2009, Kim et al. reported 4 cases of skull repair with PEEK mesh. All patients were followed up for 16 to 20 months. All patients had no 


\section{Clinical application of triangular parabolic PEEK mesh with hole button produced by combining CAD, FEM and 3DP into cranioplasty}

infection and other complications such as exposure and dislocation of implant, while their aesthetical and neurological function has been improved. However, the long-term follow-up data of Thien showed that the total complication rate and failure rate of PEEK mesh group and titanium mesh group were $25.0 \%$ vs. $27.8 \%$ and $12.5 \%$ vs. $25 \%$ respectively, But his follow-up began after the operation of the decompression of the bone flap [13]. Another important factor to consider as implantation material is its biomechanical properties. PEEK has elastic modulus which is close to the one of the cortical bone (peek, $\mathrm{E}=3 \sim 4 \mathrm{GPa}$; cortical bone, $\mathrm{E}=4 \sim 18 \mathrm{MPa}$; titanium, $\mathrm{E} \approx 110 \mathrm{GPa}$ ), which means, PEEK compared with titanium is easier for bone integration rather than bone loss, thus reducing the failure rate of implant $[15,16,22]$. Although the molecular chain structure of PEEK exhibits relative rigidity, it is quite flexible and can be reconciled with large deformed plastic flow under uniaxial tension and compression. At present, a large amount of scientific evidence supports PEEK's optimistic ability of anti-fatigue and anti-fracture. In our project, PEEK repair has no major deformation $(\varepsilon=9.053 \mathrm{e}-7)$ under the action of $2000 \mathrm{~N}$, of which the force nephogram and stress ribbon image also showed no large red or yellow area (which means that the repair is bearing a uniform force and without plastic deformation). The result is similar to that from Bernd Lethaus' mechanical stress experiment. The fracture force of the PEEK repair is $24.2 \sim 24.5 \mathrm{KN}$, which is higher than the force causing a skull fracture, of which corresponding deformation value is $8 \sim 8.4 \mathrm{~mm}$, After the equivalent force is applied to the titanium mesh, although the titanium mesh does not break, the peripheral bone cracked while PEEK did not, thus he concluded that the PEEK repair could provide better brain protection than the titanium mesh does. Based on the abovementioned outstanding performance of PEEK and further indepth research and development of PEEK-mixed materials, new PEEK material is expected to replace other implant materials, and will have a wide range of prospects in clinical application.

The different design of the implant is directly related to the post-implantation effect [23]. The design concept of the triangular parabolic mesh with lock bottom is a semisubmerged mesh, which can be dissembled to 2 parts, mesh and a button. The thickness of the mesh is close to the corresponding skull thickness, size and area match to defect's. Pattern of Figure 3, the thickness is $3.96-7.98 \mathrm{~mm}$, the size is $10.5 \times 12.5 \mathrm{~cm}$, these values are obtained by accurate measurement on Figure 2 with CAD software (mimics 17.0), the inner ring has a large area of through holes with a hole diameter of $2.1 \mathrm{~mm}$, a hole spacing of $2.4 \mathrm{~mm}$ (Table 2), which purpose is: 1) Drainage, to avoid the formation of closed lacunae or subdural effusion and/ or hematoma; 2) To promote fibroblasts, microvascular and others' proliferation, thus to improve post-implantation stability and increase bone integration; 3) To promote internal and external nutrients exchange and absorption of inflammatory cells and inflammatory mediators [21]. Theoretically, perforation will affect the mechanical properties of the implant, while according to the proof of Brennan et al. there's no statistical evidences proved changes of the mechanical properties of the implant with evenly-distributed small holes. Outer ring will be solidified to guarantee uniform distribution of concentrated force and to connection of buttons, so that, there will no fracture and buckling of the prosthesis. The lock button was designed to shorten the time of operation and as the fixation conform to the mechanics distribution. The density of the defect bone was detected by CAD software before the lock button was placed, the position and number of the lock is determined by repeated analysis and contrast with FEM. When we designed the lock button of prosthesis for the patient, we have experienced 5 locks, 6 locks and changed the size of the lock, the position and the stress-strain analysis in the solidified scope (Figures 5 and 6), and finally we considered 5 lock button (Figure 3), thickness of lock button is $1 \mathrm{~mm}$, area is $21.6 \mathrm{~mm}^{2}$, hole diameter is $2 \mathrm{~mm}$ (Table 2), the stress is evenly distributed under $2000 \mathrm{~N}$ static direct force, model of triangular parabolic mesh with hole lock bottom $(\sigma=5.7228 \mathrm{e} 6)$, triangular parabolic with a hole lock button $(\varepsilon=9.053 \mathrm{e}-7)$; defect skull $\sigma=4.1904 \mathrm{e} 6$, defect skull $\varepsilon=1.9363 \mathrm{e}-7$, designed triangular parabolic mesh with hole lock bottom was manufactured by 3DP, can be directly used for clinical implantation after high temperature steam and ultraviolet disinfection, which will be fixed by self-tapping screws with a diameter of up to $2 \mathrm{~mm}$.

Table 2. Macro design of implant of triangular parabolic PEEK mesh with hold lock button.

\begin{tabular}{llllc}
\hline Macro design & Thickness & Area & Diameter & Quantity \\
\hline Range (PEEK mesh) & $3.96-7.98 \mathrm{~mm}$ & $10.5 \times 12.5 \mathrm{~cm}$ & $2.1 \mathrm{~mm}$ & $2.4 \mathrm{~mm}$ \\
\hline Range (Lock button) & $2 \mathrm{~mm}$ & $21.6 \mathrm{~mm}^{2}$ & $1 \mathrm{~mm}$ & $2.0 \mathrm{~mm}$ \\
\hline
\end{tabular}

Digital human is the virtual simulation of human models which can be seen in all directions and can be manipulated. It is digitalizing the human structure through information technology and computer technology, when three-dimensional reconstruction, and lastly processing with virtual reality technology. CAD software mimics 17.0 can convert ("3D calculation") two-dimensional image data (Figure 1) into a visual 3-dimensional 1: 1 anatomical model (Figure 2). On the one hand, the model can accurately duplicate the deformed state, which intuitively and detailed display the anatomical structure of the craniofacial bone tissue and the defective, what is conducive for the surgeon to understand the degree of deformity and anatomical details more conveniently, comprehensively and intuitively; on the other hand, it enables a preoperative simulation, which can reduce the difficulty of surgery, reduce the operation time and improve efficacy. 
Meanwhile, it can facilitate the communication between doctors and patients to reach a consensus. In addition, CAD software can also measure the density of the model bone (average density $\left.=1.45 \mathrm{~g} / \mathrm{cm}^{3}\right)$, defect size $(10.5 \times 12.5 \mathrm{~cm})$, thickness (3.96-7.98 $\mathrm{mm})$, and can accurately design highlymatched implants when combining matic 8.0 or other software [24-26]. Developed three-dimensional model of skull and prosthesis need to be exported in STL/DICOM/GPEG format so that it can be operated in other software such as 3DP, FEM, and can be used as papers figures, etc. In our operation, we firstly export the model in STL format for a grid division (Figure 4), then 3DP it for clinical use after FEA. FEM is a collection of many units with finite size which are discrete from substance for solving continuum mechanics problems. They are characterized by high efficiency, effectiveness and ease of operation. They are widely used in clinical complex mechanics study. In our study, the bone and the prostheses were presumed as homogeneous continuous linear elastomers $[27,28]$ and were divided by solid tetrahedral and swept meshes (number of nodes is 1586622, number of units is 1019930). This way ensures both the accuracy of the analysis and low consumption of the computer's CPU. A vertical 2000 $\mathrm{N}$ static force was applied in the central area of a $7 \mathrm{~mm}$ diameter to simulate situations such as falling, car hit, heavy smash and other brain trauma, and then the maximum stress of 5-lock-botton mesh (triangular paraboloid mesh with lock button model $\sigma=5.7228 \mathrm{e} 6$; defective bone $\sigma=4.1904 \mathrm{e} 6$ ) and maximum strain of 5-lock-botton mesh (triangular paraboloid mesh with lock button model $=9.053 \mathrm{e}-7$; defective bone $\varepsilon=1.9363 \mathrm{e}-7$ ) was obtained by stress-strain analysis, the corresponding stress nephogram and stress ribbon image showing that the concentrated force distribution is relatively uniform (Figure 6), which means that the mechanical properties of 5-lock-button mesh are better than the ones of 6lock-button mesh (Figure 5), and is not easy to cause fracture and deformation after implantation. The concentrated force distribution of 6-lock-button mesh is uneven and concentrated on the forehead, the orbital and temporal bone, with the maximum stress (triangular paraboloid mesh with lock button model $\sigma=2.9068 \mathrm{e} 7$; defective bone model $\sigma=1.4687 \mathrm{e} 7$ ) and the maximum strain (triangular paraboloid mesh with lock button model $\varepsilon=2.1364 \mathrm{e}-4$; defective bone model $\varepsilon=4.4854 \mathrm{e}-5$ ). Tsouknidas also used FEM for assessing the mechanical properties and brain protection effect of PMMA and Ti6Al4V, and he argued that the high stress indicated the failure of heterogeneous graft implantation, excessive strain of which will potentially increase the intracranial pressure thus cause a brain damage [14]. The same theory is also confirmed when Beainy's use FEM to study biomechanical property changes of autologous bone for Cranioplastyin a trauma [11]. Although Lethaus says that mechanical tensile strength of PEEK is lower than that of titanium (both PEEK and titanium's tensile strengths are higher than skull's), PEEK has a high-resistant property and absorb impact energy better than titanium do, and has a low probability of peripheral bone burst, which is consistent with our conclusion from the FEA on our model [29]. And it also complies with the results of the impact ball test (titanium with a denaturation, PEEK without a denaturation, Figure 7). Cover-like 3-dimensional titanium mesh made by dry pressing will have the above-mentioned deficiency in clinical Cranioplasty, surely these deficiencies are related to many factors, of which major one is whether the mechanical properties' integrity of the prosthesis can be assured or not, especially when the prosthesis will be used for complex-structure parts such as the facies frontalis. Selective laser sintering of 3DP (SLS-3DP) utilize carbon dioxide laser beam to sinter polymer powder material (PEEK) to form a solid 3-dimensional implant. When the implant is made with SLS-3DP, the upper layer of the laser beam selectively scanned on the surface of the powder according to the cross-sectional fault data from the 3D printing system software. When the laser beam interacts with the powder, the temperature of the powder rapidly rises and the powder melt into the liquid, the liquified powder dripping into the lower layer will quickly solidify and fuse together to form a solid entity, such layered processing, superposition forming will be utilized to customize the individual implants, different from traditional materialcutting manufacturing, 3DP have obvious advantages on both material saving and time-consuming of manufacturing. Naomi et al. contend that 3DP is the best choice for making highprecision, high-detail entities [30,31]. Hutmacher et al. have a consensus on that $3 \mathrm{DP}$ can print out various complex biocompatible implants without changing mechanical properties of the materials [17,32]. Murphy and others also support than 3DP can produce bioactive materials, tissues, organs such as blood vessels, kidneys [33,34]. What is important is its low cost of 3DP, among which SLS-3DP is still relatively expensive, but still cost effective when considering its high precision after sintering and that bone growth factor can be added. In our manufacturing, the defective skull (polyvinyl chloride) and the implant (PEEK, triangular paraboloid mesh with lock button) were printed at the same time, and the degree of fitness and surface profile were confirmed again in vitro (the aim was to ensure that the implant will completely fit into the defect part of the patients), then the post-processing such as polishing, packaging, UV disinfection and others will be finished.
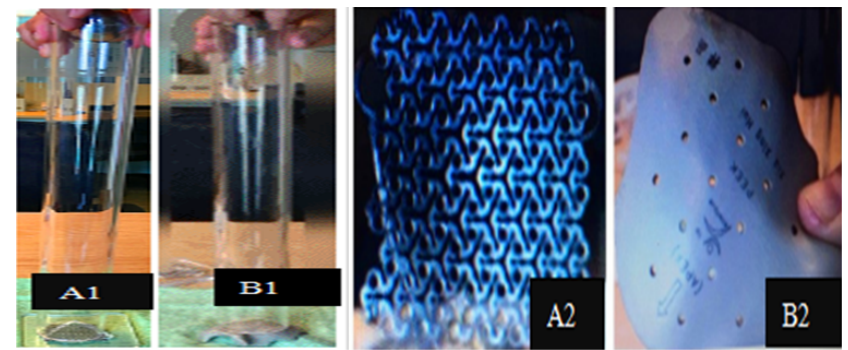

Figure 7. Ball impact test. A1: Three-dimensional titanium mesh formed by dry pressing; B1: PEEK mesh combining CAD, FEM, 3DP manufacturing, impact speed: 3.1/s, impact energy: $1.8 \mathrm{~J}$; A2 slight deformed; B2: No morphological changes.

Although the design and manufacturing process of the implant is complex, they are less time-consuming and ultimately can provide the patient cranioplasty with high matching, complete mechanical properties to ensure a good postoperative looks, less postoperative complications, less operation time and 
length of stay in hospital. However, there are still some limitation in our study, such as the lack of fracture and fatigue analysis for implant, mechanical impact of physical experiments and its results comparison (with titanium mesh, no lock button PEEK, etc.) in clinical application, we will improve this part of the work later. Meanwhile, we will also consider the addition of carbon fiber or hydroxyapatite (HA) into the PEEK material to further improve the mechanical properties of the material and induce proliferation of fibroblasts, osteoblasts, and microvascular. We believe that with the emergence of new materials, new technology, cranioplasty can reshape skull defects to a greater extent, and restore the original body beauty with less complications and low medical expenses, so that patients can be optimistic, satisfied with the surgery and lead a good life.

\section{Acknowledgment}

Thanks to materialise, Geomagic, Siemens PLM software, ANSYS company for providing software support and to Xin Zhang for software technology operation guidance, and thanks also to china are 3D company foe give SLS machine.

\section{Conflict of Interest}

The author claims that there is no competitive financial conflict of interest.

\section{References}

1. Kolias AG, Kirkpatrick PJ, Hutchinson PJ. Decompressive craniectomy: past, present and future. Nat Rev Neurol 2013; 9: 405-415.

2. Cooper DJ, Rosenfeld JV, Murray L, Arabi YM, Davies AR, D'Urso P, Kossmann T, Ponsford J, Seppelt I, Reilly $\mathrm{P}$, Wolfe R. Decompressive craniectomy in diffuse traumatic brain injury. $\mathrm{N}$ Engl J Med 2011; 364: 1493-1502.

3. Nitta N, Nozaki K. Treatment for large cerebral infarction: past, present, and future. World Neurosurg 2015; 83: 483-485.

4. Badri S, Chen J, Barber J, Temkin NR, Dikmen SS, Chesnut RM, Deem S, Yanez ND, Treggiari MM. Mortality and long-term functional outcome associated with intracranial pressure after traumatic brain injury. Intensive Care Med 2012; 38: 1800-1809.

5. Hutchinson PJ, Kolias AG, Timofeev IS, Corteen EA, Czosnyka M, Timothy J, Anderson I, Bulters DO, Belli A, Eynon CA, Wadley J, Mendelow AD, Mitchell PM, Wilson MH, Critchley G, Sahuquillo J, Unterberg A, Servadei F, Teasdale GM, Pickard JD, Menon DK, Murray GD, Kirkpatrick PJ. Trial of decompressive craniectomy for traumatic intracranial hypertension. $\mathrm{N}$ Engl J Med 2016; 375: 1119-1130.

6. Juttler E, Unterberg A, Woitzik J, Bosel J, Amiri H, Sakowitz OW, Gondan M, Schiller P, Limprecht R, Luntz S, Schneider H, Pinzer T, Hobohm C, Meixensberger J, Hacke W. Hemicraniectomy in older patients with extensive middle-cerebral-artery stroke. $\mathrm{N}$ Engl J Med 2014; 370: 1091-1100.

7. Camara-Lemarroy CR, Gongora-Rivera F, Arauz A. Hemicraniectomy for older patients in low-income countries? World Neurosurg 2014; 82: 840-841.

8. Baena JU, Thomas DG. Cranioplasty. Lancet 1976; 2: 968-969.

9. Andrabi SM, Sarmast AH, Kirmani AR, Bhat AR. Cranioplasty: Indications, procedures, and outcome-An institutional experience. Surg Neurol Int 2017; 8: 91.

10. Mah JK, Kass RA. The impact of cranioplasty on cerebral blood flow and its correlation with clinical outcome in patients underwent decompressive craniectomy. Asian J Neurosurg 2016; 11: 15-21.

11. Beainy F, El AC, Abousleimane Y, Mapstone T, Beidas O, Workman M. Biomechanical effects of cranioplasty for defects using autogenous calvarial bone. J Craniofac Surg 2012; 23: 152-155.

12. Neovius E, Engstrand T. Craniofacial reconstruction with bone and biomaterials: review over the last 11 years. J Plast Reconstr Aesthet Surg 2010; 63: 1615-1623.

13. Thien A, King NK, Ang BT, Wang E, Ng I. Comparison of polyetheretherketone and titanium cranioplasty after decompressive craniectomy. World Neurosurg 2015; 83: 176-180.

14. Tsouknidas A, Maropoulos S, Savvakis S, Michailidis N. FEM assisted evaluation of PMMA and Ti6Al4V as materials for cranioplasty resulting mechanical behaviour and the neurocranial protection. Biomed Mater Eng 2011; 21: 139-147.

15. Kurtz SM, Devine JN. PEEK biomaterials in trauma, orthopedic, and spinal implants. Biomaterials 2007; 28: 4845-4869

16. Panayotov IV, Orti V, Cuisinier F, Yachouh J. Polyetheretherketone (PEEK) for medical applications. J Mater Sci Mater Med 2016; 27: 118.

17. Kung WM, Chen ST, Lin CH, Lu YM, Chen TH, Lin MS. Verifying three-dimensional skull model reconstruction using cranial index of symmetry. Plos One 2013; 8: e74267.

18. Boinard E, Pethrick RA, MacFarlane CJ. The influence of thermal history on the dynamic mechanical and dielectric studies of polyetheretherketone exposed to water and brine. Polymer 2000; 41: 1063-1076.

19. Li HM, Fouracre NMJG, Society IDAE. The effects on polyetheretherketone and polyethersulfone of electron and/spl gamma/irradiation. IEEE Transactions Dielect EL IN 1999; 6: 295-303.

20. Renaud M, Farkasdi S, Pons C, Panayotov I, CollartDutilleul PY, Taillades H, Desoutter A, Bousquet P, Varga G, Cuisinier F, Yachouh J. A new rat model for translational research in bone regeneration. Tissue Eng Part C Methods 2015.

21. Rivard $\mathrm{CH}$, Rhalmi $\mathrm{S}$, Coillard $\mathrm{C}$. In vivo biocompatibility testing of peek polymer for a spinal 
implant system: a study in rabbits. J Biomed Mater Res 2002; 62: 488-498.

22. Kim MM, Boahene KD, Byrne PJ. Use of customized polyetheretherketone (PEEK) implants in the reconstruction of complex maxillofacial defects. Arch Facial Plast Surg 2009; 11: 53-57.

23. Lethaus B, Safi Y, ter Laak-Poort M, Kloss-Brandstatter A, Banki F, Robbenmenke C, Steinseifer U, Kessler P. Cranioplasty with customized titanium and PEEK implants in a mechanical stress model. J Neurotrauma 2012; 29: 1077-1083.

24. Fazel A, Aalai S, Rismanchian M, Sadr-Eshkevari P. Micromotion and stress distribution of immediate loaded implants: a finite element analysis. Clin Implant Dent Relat Res 2009; 11: 267-271.

25. Sun W, Lal P. Recent development on computer aided tissue engineering-a review. Comput Methods Programs Biomed 2002; 67: 85-103.

26. Pahr DH, Zysset PK. From high-resolution CT data to finite element models: development of an integrated modular framework. Comput Methods Biomech Biomed Eng 2009; 12: 45-57.

27. Dean D, Min KJ, Bond A. Computer aided design of large-format prefabricated cranial plates. J Craniofac Surg 2003; 14: 819-832.

28. Bergkvist G, Simonsson K, Rydberg K, Johansson F, Derand T. A finite element analysis of stress distribution in bone tissue surrounding uncoupled or splinted dental implants. Clin Implant Dent Relat Res 2008; 10: 40-46.
29. Ausiello P, Franciosa P, Martorelli M, Watts DC. Effects of thread features in osseo-integrated titanium implants using a statistics-based finite element method. Dent Mater 2012; 28: 919-927.

30. Zopf DA, Hollister SJ, Nelson ME, Ohye RG, Green GE. Bioresorbable airway splint created with a threedimensional printer. N Engl J Med 2013; 368: 2043-2045.

31. Lee $N$. The lancet technology: 3D printing for instruments, models, and organs? Lancet 2016; 388: 1368.

32. Hutmacher DW, Sittinger M, Risbud MV. Scaffold-based tissue engineering: rationale for computer-aided design and solid free-form fabrication systems. Trends Biotechnol 2004; 22: 354-362.

33. Murphy SV, Atala A. 3D bioprinting of tissues and organs. Nat Biotechnol 2014; 32: 773-785.

34. Zadpoor AA, Malda J. Additive manufacturing of biomaterials, tissues, and organs. Ann Biomed Eng 2017; 45: 1-11.

\section{*Correspondence to}

Rongde Zhong

Department of Neurosurgery

Songgang People's Hospital of Baoan District

PR China 